to extend their 7 -year certificate to a 10 -year certificate. For those Diplomates who certified or recertified in 2006 and who began MC-FP in 2007, close to 8,000 have successfully completed Stage 1 and are currently in Stage 2.

The first 3-year stage of the MC-FP process includes completing either 3 Part II Modules (SAMs), or 2 Part II Modules and 1 Part IV Module (PPM or approved alternate). Stage 2 requirements include 2 Part II Modules (SAMs) and 1 Part IV Module (PPM or approved alternate). These requirements may be completed anytime prior to the deadline. The ABFM Web site will immediately indicate the 3-year certificate extension upon Diplomates' completion of Stage 2 requirements.

The Diplomates who certified or recertified in 2007, and who began MC-FP in 2008, must complete their Stage 1 requirements by December 31, 2010. To date, close to 3,800 of the 2008 cohort have completed 1 or more SAM and are on track to complete their Stage 1 requirements by the end of the year.

Diplomates who certified or recertified in 2008 have until December 31, 2011 to complete Stage 1 requirements.

Diplomates who certified or recertified in 2009 may now begin working on the MC-FP Modules at their convenience. Stage 1 requirements due by December 31,2012 .

In order to help all Diplomates keep track of their progress in MC-FP, the ABFM has updated its Web site to reflect the 7-year or 10-year track chosen by the Diplomate. All Diplomates are encouraged to visit the ABFM Web site (http://www.theabfm.org) and login to the physician's portfolio section. The ABFM Web site now publicly reports MC-FP status as part of Diplomate certification status.

Jane Ireland

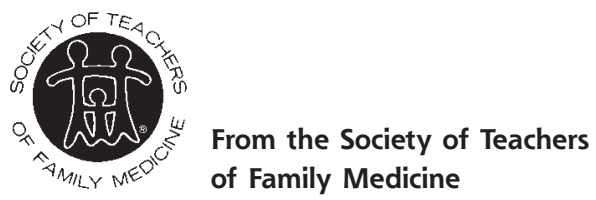

Ann Fam Med 2010;8:275-277. doi:10.1370/afm.1130.

\section{NEW WEB-BASED COURSES FOR IMG RESIDENTS AVAILABLE}

The Society of Teachers of Family Medicine (STFM) has developed a new series of Web-based courses for incoming International Medical Graduate residents. These courses were created to better prepare residents who may be unfamiliar with the role of the family physician in the United States and to familiarize them with the US health care system and residency training programs.

Many residents who have trained outside the US health care system in medical school have good knowledge of how clinical medicine is practiced from a scientific standpoint. However, the US system is often daunting: private insurers, government funders, regulators, patients, and families all have different expectations of physicians. STFM's new Web-based courses are designed to help new residents take the guesswork out of participating in the health care system, working with patients and families in the US culture, and finding a path in the practice of family medicine.

Since many STFM members are often teachers of residents who have no familiarity with the US health care system, we think these new courses will be of interest to most STFM members and their residency colleagues. These courses will allow new IMG residents to be better prepared to begin their clinical trainingby teaching practical skills such as:

- what is Medicaid and how does it work?

- how to drape a patient for privacy

- how to do a SOAP note

The courses to be offered include:

- The US health care system

- Expectations of American patients

- Communication with patients and families

- Operations of a family medicine residency program

- Succeeding in a US family medicine residency program

\section{Background}

An initial needs assessment was led by Deb Simpson and colleagues from STFM, which indicated the areas of need from both program faculty and IMG trainees. This was the basis of curriculum development for the workshop series launched in 2007 for IMG trainees.

The courses included:

- IMG Entering Resident Academy, held in Philadelphia, Pennsylvania, May 18-20, 2007 with 24 attendees

- Applicant Academy, held in Chicago, Illinois, September 16-18, 2007 with 9 attendees

- Entering Resident workshop (2008) (the higher attended of the 2 in 2007) was offered in Philadelphia in May and in Chicago in June

The attendees at these workshops in 2007 and 2008 rated the content and the presenters very high, and STFM received good feedback on the program. However, STFM had hoped to be able to reach a broader audience of residents and programs. After 
many conversations with program directors, several accessibility challenges became apparent:

- The timeframe made it extremely difficult for programs to send their incoming residents-there simply isn't enough time between the match and the date residency begins

- Residents are busy with transition and moving in this period, and IMGs are especially busy getting visas, which typically don't start until employment begins and they move into the United States

- It was difficult to communicate the availability of the workshops to entering residents since those names and addresses are not even compiled until after the workshops are over

- The production and delivery expenses required a registration fee of $\$ 899$, which didn't build in enough margin for STFM to cover costs and yet was too expensive for programs to send more than 1 resident

The strengths of these workshops:

- It was an ideal learning environment for incoming IMGs

- The faculty members involved developed both a good curriculum and a well-received training experience

- IMG new residents were given the chance to learn from faculty who were seasoned IMGs and could offer tips and advice from the very valuable "I've been there" perspective

- The workshops do address an obvious need: training for IMG new residents on the US health care system and how family medicine residencies operate

In 2009, with increasing numbers of IMG residents coming into family medicine, STFM needed to increase the accessibility to the courses in a format that would be convenient and low-cost. The goal was to preserve the strengths of the live courses, while making it possible for a recent medical school grad to take the courses at 3:00AM in a location half-way around the globe.

The course info can be found on STFM.org along with a direct link to eLeap, where the courses will be hosted. eLeap is a service that provides e-learning to many organizations and corporations.

There is a fixed path through the material in each module, with quizzes interspersed. Learners can "bookmark" their place in the module and return when they'd like.

The courses are SCORM* compliant. Sharable Content Object Reference Model (SCORM) is a collection of standards and specifications for Web-based e-learning.
The courses are priced affordably:

- $\$ 59$ per course or $\$ 159$ for all 5 courses and a certificate of completion

- \$990 for a residency program to purchase the courses for all their residents and receive weekly reports on progress

The program package includes more than access to the courses. Program directors and faculty who choose to purchase the courses for all residents will receive weekly reports for 8 weeks on the progress of all residents, including who has completed which modules and what scores they receive on their quizzes. Programs have the option of suggesting or even requiring that their incoming residents repeat the courses if they receive low scores.

Programs will be able to be more confident that their incoming IMG residents have a base knowledge of the US Healthcare system and FMRP operations when they arrive for training. This will save the program faculty and staff valuable time in orientation of new IMG residents.

Each course includes several lessons, which may include audio and video clips powerpointpresentations, e-books, and quizzes. Each course incorporates audio files of residency faculty members sharing tips, stories, advice on what to avoid, and "best practices." The stories that faculty members share include scenarios of residents who have made mistakes and advice on how situations could have been handled.

\section{Descriptions of the Courses \\ The US Health Care System}

Learn the basic dynamics of the US health care system, including delivery and payment methods. What is the focus of family medicine? How does it differ from general medicine, internal medicine, community medicine? Who are the AAFP, the AMA, and the different professional groups? What are the expectations of the public regarding family physicians?

\section{Expectations of American Patients}

This course includes information about the expectations of the very diverse US patient population. It covers the specifics of professionalism (white coat) to the broader issues of how the US culture affects patients' interactions with their physician. This course teaches how to be sensitive and responsive to patients' culture, age, gender, sexual orientation, religion, and disabilities. Learners will understand necessary patient education and specific responses to patients in a US culture, including what to say when the patient has searched their illness online or when they request a medication they saw advertised on television. 
Communication with Patients and Families

This course will teach patients' expectations of a family physician including the medical interview, how to gain trust, and how to communicate with patient's family members. Decision makers and protocol for involving family members is quite varied in different cultures, learners will understand what US patients and their families will expect and how to successfully interact with them.

Operations of a Family Medicine Residency Program Learn about presentation and documentation skills you will need as a resident, expectations of facultyresident interactions and hospital and clinic rituals in medical education. Roles, expectations, training, differences among students, interns, residents, fellows, faculty will be included in this course. Become aware of what happens when, and what the expectations will be of a resident.
Succeeding in a US Family Medicine Residency Program

Learn about the documentation, paperwork and form that are necessary in a US family medicine residency program. Review highlights of Institution, Department and ACGME Policy and Procedures, Rules and Regulations received upon employment.

For more information on STFM's Web-based courses for incoming IMG residents see http://www. STFM.org. For specific questions, contact Jill Haught at STFM at jhaught@stfm.org.

Angela Broderick, CAE

STFM Deputy Executive Director

Katby Zoppi, PbD, MPH

Community Healtb Network FMR, Indianapolis, Indiana

\section{CHANGE-OF-ADDRESS FORM FAMMILY MEDICINE}

Please complete this form and mail to the following address or fax to Annals Circulation at 913-906-6080:

Annals of Family Medicine, Circulation Department, 11400 Tomahawk Creek Pkwy, Leawood, KS 66211-2680

Check if member of sponsoring organization:

$$
\begin{array}{ll}
\square \text { AAFP } & \square \text { ABFM } \square \text { STFM } \square \text { ADFM } \\
\square \text { AFMRD } & \square \text { NAPCRG } \square \text { CFPC }
\end{array}
$$

ID number from label on your journal cover

OLD Information (Please print.)

Name

Company (if applicable)

Address (Street plus Apt or Ste)

\begin{tabular}{ll}
\hline City & State \\
\hline Country & Postal Code (9-digit ZIP for US) \\
\hline Telephone & Fax \\
\hline E-Mail &
\end{tabular}

NEW Information (Please print.)

\begin{tabular}{ll}
\hline Name \\
\hline Company (if applicable) & \\
\hline Address (Street plus Apt or Ste) & \\
\hline City & Postal Code (9-digit ZIP for US) \\
\hline Country & Fax \\
\hline Telephone & \\
\hline E-Mail
\end{tabular}

